\title{
A Hipótese de Declínio da Soberania dos Estados Modernos: A crise econômica na União Europeia como palco do poder de influência dos grupos econômicos e financeiros em relação às tomadas de decisão dos Estados Europeus
}

\author{
Carlos Roberto da Silva \\ Graduado em Direito pela Universidade do Vale do Itajaí - \\ Univali. Pós-graduado em Direito Civil, mestre em Ciência \\ Jurídica e doutorando em Ciência Jurídica, em dupla titu- \\ lação, pela Universidade do Vale do Itajaí e Universidade \\ de Alicante, na Espanha. Professor do curso de Direito \\ da Universidade do Vale do Itajaí - Univali. Magistrado \\ Iotado na Vara da Fazenda Pública da Comarca de Itajaí.
}

\section{Resumo}

0 presente artigo tem por objetivo analisar a situação global da Soberania e os fatores que atualmente enfraquecem-na, como as influências não políticas no ordenamento jurídico interno e a expansão da Democracia transnacional. Mostra-se, com essa exposição, que os grandes blocos econômicos e a imprensa acabam por influenciar o processo de criação e aplicação das leis, ameaçando cada vez mais a Soberania do Estado em questão. Discute-se, também, a atual situação da União Europeia, instituição transnacional que representa a flexibilização dos conceitos de Soberania e Democracia Transnacional em meio à crise não apenas econômica, mas também política, que se estende através dos anos e dos pacotes econômicos, causando uma redução nos padrões de vida provocada, principalmente, pelo desemprego. Ao final, analisa-se a situação geral do Estado Democrático de Direito concebido pela modernidade ante os desafios dos novos tempos, que tendem a enfraquecer seu poder soberano.

Palavras chave: Soberania. Globalização. Democracia. 
The Hypothesis of a Decline in the Sovereignty of Modern States: The economic crisis in the European Union as a stage for the influential power of the economic and financial groups in relation to decision taking of the European States

\begin{abstract}
This article aims to analyze the global situation of Sovereignty and the factors that currently undermine it, like non-political influences in the domestic legal system and the expansion of transnational democracy. It is shown, with this exposition, that the large economic blocs and the press end up influencing the process of creation and application of the laws, increasingly threatening the sovereignty of the State in question. It also discusses the current situation of the European Union, transnational institution that represents the flexibilization of the concepts of Sovereignty and Transnational Democracy, amid the crisis, not only economic but also political, which extends itself through the years and through the economic stimulus packages, causing a reduction in living standards, provoked mostly by the unemployment. Finally, it analyses the general situation of the Rechtsstaat conceived by modernity, facing the challenges of the new times which tend to weaken its sovereign power.
\end{abstract}

Keywords: Sovereignty. Globalization. Democracy.

\title{
Sumário
}

1 Soberania. 2 Globalização. 3 União Europeia. 4 A crise da democracia. 5 Considerações Finais. 6 Referências. 


\section{SOBERANIA}

A Soberania pode ser compreendida, no âmbito interno de cada Estado, como a qualidade do ente estatal que permite a criação de leis e a imposição coativa dessas regras de conduta, sendo a única instituição, dentro de seu espaço geográfico, que possui esse poder. Do ponto de vista externo, pode ser vista como a capacidade que possui um Estado de ser reconhecido como autoridade máxima de seu território por outros Estados soberanos, sendo competente para a escolha política das diretrizes de governo aplicáveis por sua estrutura funcional.

Há, portanto, dentro dessa compreensão, o aspecto interno e externo, ou dupla função, do termo Soberania em relação ao papel a ser desenvolvido pelo Estado Moderno Democrático de Direito. É possível até pensar que não haveria razão para a existência desse ente estatal, ou não existiria para o objetivo de organizar a vida em sociedade, caso não alcançasse esse patamar de autonomia e de poder de decisão. ${ }^{1}$

O conceito de Soberania, segundo Giddens:

Soberano é o Estado cuja organização política tem a potencialidade, dentro de um território ou territórios delimitados, de produzir leis e efetivamente sancionar a sua manutenção; exercer um monopólio sobre o controle dos meios de violência; controlar políticas básicas relacionadas à política interna ou à forma administrativa de governo; e o acesso aos frutos de uma economia nacional que sejam a base de sua receita (2001, p. 296).

\footnotetext{
${ }^{1}$ Como afirma Cleveland: "Globalization in the form of new norms and alternative actors is examined to determine their effects upon sovereignty. Examining the current practice of intervention in the international system, the effect of globalization on large and small states as well as alternative actors that are both supra-national and sub-state, demonstrates that states will remain the locus of sovereignty despite claimsthat the state is nolonger relevant. The disaggregation of the concept of the state from its link to the concept of sovereignty allows for the examination of challenges tothe monopoly of the state on sovereignty”. In: Cleveland, Clayton J. Globalization and Sovereignty: The Persistence of an International Norm. University of Oregon: Eugene, 2006. p. 2.
} 
A Soberania, no entanto, partindo-se da ideia central de sua concepção, no sentido da absoluta independência do ente estatal em optar por decisões que lhe pareçam mais viáveis aos objetivos da população que representa, e de ser o foco central e único das políticas internas, encontra-se ameaçada e enfraquecida. Em hodierno não se pensa apenas em ameaças externas ao exercício desse poder de decisão por parte do Estado, por meio de invasões bélicas com o uso da força, mas sim em uma força invisível, e possivelmente mais poderosa, derivada do poder econômico transnacional dos organismos e instituições financeiras ou econômicas (Resende, 2011).

Esse poder exercido pelos grandes conglomerados econômicos e financeiros dita regras cuja observância ultrapassam as fronteiras territoriais dos Estados soberanos. São regras não somente ligadas ao campo da economia e das finanças, e não apenas direcionadas às pessoas, no aspecto de consumo, moda, e convivência, mas também relacionadas às políticas de governo dos Estados. Aí, portanto, reside o poder que enfraquece a Soberania estatal, antes não questionada nos tempos da modernidade. ${ }^{2}$

Incontestável no mundo em que vivemos o exercício dessa influência, sobretudo em relação àqueles Estados com menor envergadura econômica, e que assim são forçados a ceder e trilhar cartilhas comportamentais escritas em grandes escritórios por tecnocratas cuja formação econômica não está centrada em conceitos como os de Democracia, Soberania, Meio

\footnotetext{
${ }^{2}$ Como demonstra Paulo Cruz: "Essa atividade 'parapolitica', gerada a partir dos centros financeiros, está permitindo que as corporações transnacionais ocupem, de forma imperceptivel, sem revolução, sem mudanças na lei nem nas constituições, através do simples desenvolvimento da vida cotidiana, os centros materiais vitais da Sociedade. Os cidadãos estão sendo jogados a um mundo de redes anônimas, no qual as empresas multinacionais se transformam no modelo de conduta. A nova utopia é a de um mercado da informação e da comunicação totalmente integrados graças às redes eletrônicas e de satélites, sem fronteiras, funcionando em tempo real e de forma permanente". In: Cruz, Paulo Márcio; Xavier, Grazielle. Democracia transnacional. Disponível em: <http://www.conpedi.org.br/manaus/ arquivos/anais/salvador/paulo_marcio_cruz.pdf>. Acesso em: 15 jan. 2013.
} 
Ambiente, Crescimento Sustentável, Bem-estar Social, Solidariedade, Fraternidade e outros. Na verdade, o regramento maior dessas organizações diz respeito ao lucro a ser obtido com a atividade capitalista, lucro esse nem sempre ligado a qualquer interesse de cunho social, ou de preservação da identidade ou cultura local de uma determinada população (Beck, 1999, p. 27).

Considerando esse fenômeno - observado com maior visibilidade nos últimos tempos em decorrência das grandes crises econômico-financeiras experimentadas inclusive pelas grandes potencias econômicas mundiais, e que por isso repercutiram em todos os mercados e economias do planeta - alguns pensadores do Direito sugerem que a Soberania estatal e, por consequência, o Estado como hoje existe, está em declínio ou até em extinção, sobretudo porque o palco das grandes decisões políticas se afastou da esfera estatal, que tem se limitado a apenas formalizar e homologar as diretrizes de sua política econômica interna a partir de decisões tomadas pelos grandes grupos financeiros de abrangência mundial. Ferrajoli, nessa linha de raciocínio, afirmou que:

[...] falar da soberania e de seus eventos históricos e teóricos importa afirmar que os acontecimentos daquela formação político-jurídica particular que é o Estado nacional moderno, nascida na Europa há pouco mais de quatro séculos e exportada no século XX para todo o planeta, hoje se encontra em declínio (2002, p. 23).

Ainda que não se deseje trilhar por esse caminho possivelmente pessimista em excesso, em relação à ideia de extinção completa do Estado como concebido nos tempos da modernidade, parece certo pensar ao 
menos na hipótese de uma etapa de profundas transformações no aspecto do convívio social e no próprio convívio entre os Estados independentes e soberanos. ${ }^{3}$

A era da modernidade, iniciada com o pensamento iluminista e a proposta de alcance dos atributos da liberdade e da igualdade entre os homens - sobretudo concentrada nos aspectos da economia burguesa - já foi ultrapassada, certamente porque alcançada, plena ou satisfatoriamente. Iniciou-se, seja a partir das primeiras Constituições de cunho social do início do século 20, seja a partir do fim da segunda grande guerra, uma nova era conhecida como "a Pós-Modernidade".

Se assim compreendido, estamos vivendo, portanto, um período de novas transformações e conquistas, certamente porque hoje já se tem como incorporados ao patrimônio universal aqueles conceitos que fundaram o período de transformação para a modernidade. Busca-se, então, tendo em conta as vicissitudes e necessidades dos tempos hodiernos, novos objetivos para a resolução de questões de alcance mundial, como, por exemplo, as relacionadas ao meio ambiente, à exploração sustentável das riquezas mundiais, à diminuição da desigualdade social no planeta e outros. ${ }^{4}$

\footnotetext{
${ }^{3}$ Ensina Paulo Cruz que: “A reconstrução da Sociedade pós Estado Constitucional Moderno passa pela reabilitação do político, do social e do cultural contra a hegemonia da razão econômica. Isso implica uma redefinição ou, mais exatamente, um redescobrimento do bem comum, de um saber-viver juntos e de um novo sentido para a aventura de viver". In: Cruz, Paulo Márcio. Democracia e pós-modernidade. p. 7. Disponível em: <http://www.conpedi. org.br/manaus/arquivos/anais/campos/paulo_marcio_cruz.pdf $>$. Acesso em: 20 jan. 2013.

${ }^{4}$ Assevera Cruz: “[...] é possível uma organização política democrática adstrita aos paradigmas de participação, da política de tolerância, da distribuição da riqueza, da utilização sustentável do meio ambiente, da solidariedade e da diversidade e do sociatismo, não necessariamente nessa ordem”. In: Cruz, Paulo Márcio. Democracia e pós-modernidade. p. 4-5. Disponível em: <http://www.conpedi.org.br/manaus/arquivos/anais/campos/ paulo_marcio_cruz.pdf>. Acesso em: 20 jan. 2013.
} 
Dentro desse panorama de mudanças e conquistas, a antes mencionada força política dos conglomerados financeiros e econômicos, que reconhecidamente tem enfraquecido a Soberania dos entes estatais, como já se salientou anteriormente, encontra campo fértil para o exercício de sua pujança. É que sabidamente a saúde econômico-financeira de um Estado mostra-se como essencial para que possa enfrentar as dificuldades relacionadas à manutenção ou ao alcance de um patamar de estabilidade social reconhecido como mínimo, a partir de comparações com outros Estados (Dupas, 2009, p. 11-12).

Assim, um determinado padrão de vida, com o digno e merecido atendimento às questões ligadas à saúde, à educação, ao saneamento básico, ao lazer e a outros tantos direitos fundamentais consagrados pela maioria das Constituições modernas, não pode ser efetivado, ou experimentará expressivo retrocesso, caso evidenciado um declínio ou colapso nos cofres e na capacidade de investimento do ente estatal. $\mathrm{O}$ resultado disso será, inevitavelmente, uma crise não apenas econômica, mas também social (Cruz; Xavier, 2008, p. 2.623-2.624).

Evidenciado esse quadro, e considerando a inexorável ligação e correlação entre os mercados econômicos mundiais, também fenômeno da globalização, pode-se começar a compreender - verbo distante do aceitar - que as decisões de maior repercussão para a busca de solução das crises não sejam tomadas no âmbito interno de cada Estado, mas sim nos escritórios refrigerados das grandes instituições financeiras e econômicas com atuação mundial. Desaparece e se vê enfraquecida, assim, a Soberania dos Estados Modernos (Dupas, 2009, p. 7).

Não se pode negar, portanto, que a Soberania nesses Estados não tem sido exercida tal qual concebida em seus termos originais, à medida que influências externas, de outros Estados e de grupos financeiros mundiais, têm se mostrado cruciais para as tomadas de decisão internas, decisões essas, muitas delas, impopulares, restritivas no aspecto de avanços 
sociais obtidos com o crescimento do Estado Social, e que possivelmente não representaram a concretização da vontade da maioria dessas populações. ${ }^{5}$

A Democracia Representativa, todavia, tornou legal, no aspecto formal, as tomadas de decisão por parte desses Estados, fazendo com que essas medidas econômicas de caráter restritivo tivessem de ser cumpridas, sob pena de possível agravamento da crise e de consequências ainda mais catastróficas - ao menos foi o que sustentaram os tecnocratas. Tal aspecto ligado às repercussões dessa situação ante a Democracia será abordado nesse trabalho em tópico adiante.

O enfraquecimento da Soberania estatal, proporcionado pela atividade feroz e exigente dos grupos econômicos e financeiros, tem sido facilitado pela multifacetada vida globalizada. Esse fenômeno, do ponto de vista da velocidade dos meios de comunicação - sobretudo da Internet - ocasionou o conhecimento e a aproximação das diferentes culturas mundiais, mas, por outro lado, desnudou espaços antes desbravados apenas internamente, expondo-os e, quiçá, manipulando-os a bem dos interesses, ainda não muito bem-esclarecidos, desses que detêm o poder econômico.

\section{GLOBALIZAÇÃO}

A globalização é um fenômeno mundial de difícil conceituação. O núcleo da ideia de globalização é que, atualmente, um evento regional, que aconteça em qualquer lugar, pode ser conhecido por pessoas em todo o mundo e, ainda, pode implicar consequências em vários Estados (Cleveland, 2006, p. 6 et seq.).

\footnotetext{
${ }^{5}$ É o pensamento de Resende, quando afirma: "Inobstante os anseios de Stiglitz, não é o que se percebe na realidade mundial. Ao contrário: o conceito de soberania, que até então poderia se configurar como algo imune às influências, ilimitado e uno, poderá se confrontar com uma realidade em que o próprio Estado repassa parte de sua soberania para o exercício de Instituições privadas de caráter paraestatal. Segue à risca, assim, os programas traçados por elas, sob pena de graves sanções e repercussões pecuniárias. Esses novos fatores reais de poder, baseados em aspectos econômicos, superam as noções clássicas de soberania, minimizando o Estado frente o capital". In: Resende, Carlos Alberto. Jürgen Habermas e a crise do estado globalizado. Disponível em: <http://www.diritto.it/docs/31317-j-rgen-habermas-e-a-crise-do-estado-globalizado>. Acesso em: 15 jan. 2013.
} 
A globalização é a "intensificação das relações sociais em escala mundial, que ligam comunidades distantes, de tal maneira que acontecimentos locais são modelados por eventos ocorrendo a muitas milhas [...]” (Giddens, 1991, p. 69).

Não há que se negar os aspectos positivos desse fenômeno, à medida que se reconhece que a divulgação de conhecimento e de experiências bem-sucedidas colocadas em prática em um determinado lugar do planeta, possibilita que povos distantes, muitas vezes desprovidos dessa técnica ou saber, possam usufruir dessas benesses e melhorar sua condição de vida. Igualmente não há como evitá-lo, à medida que já se tornou disseminado e incorporado ao dia a dia das pessoas. Os avanços tecnológicos frequentes, por outro lado, apenas confirmam, reafirmam e fortalecem esse fenômeno, contribuindo com novas e eficientes ferramentas para a disseminação das informações (Cruz; Xavier, 2008, p. 2.611).

A velocidade como trafegam esses dados, no entanto, não respeita as diferenças culturais e até econômicas dos diferentes grupos sociais. Há, portanto, em decorrência do processo de globalização, um inexorável choque, que haverá de impor consequências inclusive no aspecto da Soberania estatal se considerado que um determinado padrão de vida de uma sociedade em um certo país é tido como necessário e indispensável por outra sociedade, a partir do conhecimento adquirido em um mundo globalizado e sem barreiras (Biernazki, 2000, p. 47).

Nesse campo fértil de anseios por padrões, hábitos e bens dispostos em um lugar e inexistentes em outros, surgem os grandes grupos econômicos e financeiros havidos por lucros e por novos mercados, e que atuam de forma a pressionar os Estados, diminuindo seu poder soberano de decisão. A globalização, portanto, também exerce uma efetiva influência nessa perspectiva de intromissão dos grupos econômicos e financeiros no poder soberano que deve ser exercido pelos Estados. 
A globalização possibilitou, ainda, um acompanhamento e conhecimento geral pela população mundial acerca de alguns dos grandes problemas da própria humanidade, sobretudo aqueles relacionados ao meio ambiente e às desigualdades sociais. Algumas dessas questões acabam tomando dimensões globais, deixando de representar preocupação apenas interna do Estado, passando a compor o elenco de aspirações mundiais. Nesse sentido, pode-se cogitar a hipótese de perda ou ameaça à Soberania estatal, porquanto assuntos de expressão regional passam a ter palco de discussão mais amplo. É o caso, apenas para exemplificar, das riquezas e da necessidade de preservação da floresta amazônica em relação à política ambiental aplicada pelo governo brasileiro.

Há, em tempos presentes, na União Europeia, um estágio avançado de globalização. A antiga divisão entre leste e oeste foi completamente destruída no aspecto da ampla divulgação de informações, de conhecimentos e de experiências. Não há mais muros ou barreiras político-ideológicas, e mesmo as populações que ainda não alcançaram um padrão de vida economicamente superior conhecem as benesses de modelos capitalistas cujos Estados igualmente promovem uma proteção social que garante aos seus cidadãos um padrão de vida invejável (Mello, 1999).

Ocorre que esse conhecimento generalizado, proporcionado pela globalização, não é suficiente para resolver as diferenças, ao contrário, as expõe em ainda maior evidência à medida que são graves as desigualdades sociais dos povos europeus, provocadas por décadas de políticas econômicas e sociais diferentes nos aspectos ideológicos e de ação política. Esse conflito expõe uma realidade que a união econômica da Europa não consegue esconder, e levará ainda muitas décadas para possivelmente superar (Habermas, 2002, p. 127-128).

É certo que esses Estados, podendo-se citar como exemplo o alemão, só alcançaram esse padrão econômico e social após ultrapassarem estágios difíceis, inclusive de reconstrução após sérias crises e guerras. 
Por isso, é de se reconhecer que se trata de um processo que ainda levará tempo, e que não será resolvido da noite para o dia, menos ainda por meio de medidas ou pacotes econômicos salvadores ou mágicos, passando, do contrário e precedentemente, por um período de conscientização e transformação interna de cada população e de seus governantes. ${ }^{6}$

No que diz respeito à Democracia, é possível pensar igualmente na hipótese de que a Globalização pode provocar, em termos mundiais, uma reanálise constante de seus modelos, à medida que a disseminação sem fronteiras das informações faz com que populações de outros países acompanhem o sucesso ou o fracasso de conquistas a partir da forma de Democracia que é exercida - e se é exercida - em determinado local. Essa percepção, ainda que vista a partir das lentes e vozes da mídia, acaba, mesmo que silenciosamente, formando opiniões e a até agigantando movimentos, como ocorreu em tempos próximos passados em alguns países muçulmanos, cujas populações foram às ruas e praças clamar por maior participação nas decisões políticas e por mais espaço e liberdade de manifestação.

Cogita-se, portanto, que essa aldeia global, vista por todos em uma única tela, ao expor as mazelas, ensina, por outro lado, caminhos exitosos que podem ser revisitados. Imagina-se, assim, que algumas experiências, adaptadas aos padrões comportamentais e à cultura dos povos locais, podem ser reproduzidas com sucesso, sem imposição, mas com aceitação e dentro da proposta de transformação para um mundo melhor, com padrão mais elevado de qualidade de vida às pessoas.

\footnotetext{
${ }^{6}$ Aduz Ferrer: "Como se consegue perceber, é preciso ir fundo nas propostas de reforma dos fundamentos do capitalismo. Caso não seja controlado pela sociedade, qualquer tipo de tentativa de desenvolvimento de modelos de Poder Público Transnacional será efêmero, infrutífero. E o único modo talvez de convencer os centros de comando capitalistas é demonstrar que o futuro da humanidade e o do próprio capitalismo depende dessa mudança de concepção, fazendo convergir Democracia, lucro e interesse social transnacional para o bem comum". In: Cruz, Paulo Márcio; Ferrer, Gabriel Real. A crise financeira mundial, o Estado e a Democracia econômica. Argumentum - Revista de Direito, n. 10, p. 117-136, p. 121, 2009.
} 
Nessa linha de pensamento imagina-se um lado benéfico, dentre outros possíveis, do fenômeno da globalização, dentro da perspectiva de crise da Soberania dos Estados, no sentido de facilitação das boas ideias e soluções, considerando o processo evolutivo pelo qual passaram as sociedades que hoje possuem um padrão de vida aceitável. Essa possível influência da Globalização na esfera da Soberania estatal, por meio da disseminação geral de práticas positivas, ainda que adotadas por Estados estrangeiros, poderá representar em termos práticos uma invasão benéfica no poder soberano estatal interno.

\section{UNIÃO EUROPEIA}

A União Europeia é uma união política e econômica de 27 Estados que permite liberdade de movimentação, entre os Estados-membros, de mercadorias, recursos monetários e pessoas (UE, 2006c). Tem suas raízes na Comunidade Europeia do Carvão e do Aço e da Comunidade Econômica Europeia. Com o sucesso dessas duas instituições, houve a expansão e aprofundamento das relações e o aumento do número de membros (UE, 2006a).

A criação da União Europeia implicou algumas modificações na Soberania dos Estados-membros. Há temas que fazem parte dos Tratados da União Europeia e que, por sua natureza, são deliberados no âmbito da União. Apenas os assuntos que não possuem regimento da União Europeia podem ser objeto de ações isoladas de cada Estado-membro, dentro de sua própria competência (UE, 2006b).

Pode-se cogitar a ideia de restrição ao poder soberano estatal europeu, quando, em 2011, o então presidente do Banco Central Europeu, Jean-Claude Trichet, comentou que para o desenvolvimento da União Europeia, possuindo um mercado único e um banco central único, seria viável possuir apenas um ministério das finanças que englobasse todos 
os membros da União Europeia. Ainda, comentou que a União Europeia deveria possuir mais autoridade nos casos em que países que recebem auxílio financeiro desrespeitassem regras e não cumprissem acordos, parte integrante dos pacotes de auxílios, incluindo a aplicação compulsória de medidas econômicas deliberadas pelos outros Estados-membros (The Guardian, 2011).

Não há como negar que a união dos Estados europeus teve seu berço inspirador em razão dos laços e interesses econômicos e comerciais. As diferenças regionais, étnicas, culturais e, portanto, também econômicas, são incontestes e não haverão de retroceder; do contrário, parecem ficar ainda mais expostas no mesmo ritmo de velocidade com que os ares democráticos se espalham, com a colaboração da Globalização. As crises econômicas evidenciam ainda mais essa falta de uniformidade, pois evidentemente serão os Estados mais frágeis do ponto de vista econômico - e, como tal, falando-se de Europa, citam-se aqueles do leste europeu e que abandonaram a fracassada ideia do comunismo, os que ficarão mais vulneráveis às sucessivas intempéries dos mercados. ${ }^{7}$

Esse desequilíbrio, bem-evidenciado em relação ao poder econômico e financeiro dos Estados europeus, ao contrário de afastar, justifica ainda mais a necessidade de fortalecimento da União, ainda que com interesses majoritariamente comerciais em uma primeira etapa. Aliás, com o recente fracasso das negociações para se obter zonas mundiais de livre-comércio, a formação de blocos regionais na busca do incremento dos

\footnotetext{
${ }_{7}$ Explana Cambraia: "Esta estrutura europeia é posta de forma que possuam Estados rurais $e$ Estados industrializados, o que permite o mútuo beneficio, naquilo que lhe é pertinente e mútua proteção, com subsídios de produtos, facilitação de produção, isenções tributárias, etc." In: Cambraia, Hudson de Oliveira. A globalização, seus reflexos na Soberania dos Estados e na institucionalização do Estado Democrático de Direito e os blocos internacionais: a viabilização de uma alternativa possível. Revista Eletrônica Virtuajus - PUC Minas. Disponível em: <http://www.fmd.pucminas.br/Virtuajus/1_2008/Discentes/Globalizacao.pdf>. Acesso em: 15 jan. 2013.
} 
negócios bilaterais, e consequente desenvolvimento dos Estados, tem sido uma das hipóteses de enfrentamento e de fortalecimento ante aos períodos de instabilidade.

A falada fragilização da Soberania dos Estados, no que diz respeito aos Estados Europeus, se viu evidenciada por ocasião da recente crise econômica. As medidas adotadas no âmbito financeiro e fiscal, que foram instituídas pelos Estados que se encontravam em grave crise, como o Estado grego, não foram decididas pelos próprios nacionais, mas sim por tecnocratas das instituições financeiras da Europa. Assim, apesar de terem de ser suportadas pela população grega, essas medidas restritivas, que alteravam significativamente o modo de viver da população, foram decididas por quem não haveria de suportá-las no dia a dia. A receita, portanto, foi importada e veio imposta, e a Soberania estatal enfraquecida.

Pode-se conceber a ideia de que os Estados sociais assumiram custos significativos por sua especial dedicação às áreas em que a iniciativa privada não mostrou interesse, como o atendimento à saúde e educação das camadas menos abastadas das populações, ou mesmo nos investimentos de longo prazo em infraestrutura de saneamento básico. Esse custo tornou-se pesado, e acabou prejudicando os orçamentos estatais, sobretudo naqueles países onde os governantes não foram austeros, como deveriam, com a verba pública, ou não souberam competir dentro dos novos padrões do feroz e globalizado comércio internacional. ${ }^{8}$

\footnotetext{
${ }^{8}$ Acerca do assunto, Ferrer acrescenta: "Parece claro que o capitalismo globalizado vai fazer de tudo para atenuar a atual crise financeira, sempre impondo maiores sacrifícios aos menos abastados. Mas, mesmo que haja êxito, as seqüelas serão muitas e grandes. Desemprego, aumento da pobreza e da miséria, intensificação da concentração da riqueza, mais degradação do meio ambiente, entre outras". In: Cruz, Paulo Márcio; Ferrer, Gabriel Real. A crise financeira mundial, o Estado e a Democracia econômica. Argumentum - Revista de Direito, n. 10, p. 117-136, p. 132, 2009.
} 
A ideia da união, portanto, parece se manter forte e bem-embasada em seus conceitos. Precisa, todavia, ser revista pelos governantes europeus para que possa não somente avançar a outros pontos da convivência social, mas representar, portanto, uma integração mais evidente em outros setores, com respeito às diferenças e culturas regionais. Essa revisão deve retornar ao ponto de partida, ou seja, à ideia central inicial de se construir uma união: a união comercial e o equilíbrio econômico dos diferentes componentes, ou coirmãos. Parece pouco crível supor que a União perdurará e se fortalecerá, tornando-se mais abrangente, se persistirem as diferenças econômicas. Nesse caminhar, a já mencionada influência dos poderosos grupos econômicos e financeiros deve ser mais bem absorvida pelos governos locais, por meio de medidas e decisões que não exponham aos olhos do mundo globalizado uma reconhecida fragilidade de sua Soberania. $\mathrm{O}$ ponto de equilíbrio, portanto, parece se mostrar como a solução mais adequada.

\section{A CRISE DA DEMOCRACIA}

Com a liberdade de mercados trazida pela globalização, foi inevitável a expansão das empresas multinacionais, dos grupos e conglomerados econômicos e financeiros. Não foram suficientes as fronteiras geográficas ou culturais, porquanto havia e há interesses recíprocos, seja dos próprios grupos empresariais, ávidos por mercados e lucros, seja dos Estados, para que o incremento das atividades empresariais em seus territórios pudesse representar, na mesma proporção, um incremento na qualidade de vida das pessoas.

Assim, essa expansão de mercado beneficia o país que recebe as filiais, pois os produtos antes importados passam a ser fabricados ou montados naquele local, gerando empregos (Stal; Campanario, 2010). Por sua capacidade de geração de emprego e desenvolvimento, essas empresas 
acabam por influenciar no processo de aplicação das leis trabalhistas. Tal influência recebe o nome de flexibilização trabalhista (Budel, 2002). Ainda, como afirmam Paulo Cruz e Grazielle Xavier, as empresas transnacionais estão constituindo o que chama de uma "atividade parapolítica", trazendo modificações à sociedade sem necessariamente modificar o Direito:

A ausência do político está permitindo que as grandes corporações multinacionais levem a cabo, na prática, uma autêntica tomada do poder, um verdadeiro controle do mundo a margem da política. Sob o véu de uma pretensa racionalidade econômica e por trás de uma aparência formal de apoliticidade, se está desenvolvendo, na prática, com extraordinária força, um novo tipo de política, que pode ser qualificada como "parapolítica”. Essa atividade "parapolítica", gerada a partir dos centros financeiros, está permitindo que as corporações transnacionais ocupem, de forma imperceptível, sem revolução, sem mudanças na lei nem nas constituições, através do simples desenvolvimento da vida cotidiana, os centros materiais vitais da Sociedade (Cruz; Xavier, 2008, p. 2.611-2.612).

Há, ainda, outra força capaz de influenciar a criação e manutenção de leis, direcionando a atenção dos órgãos e da população a um fato ou evento particular: a imprensa. Ainda, como afirma Albuquerque (2000, p. 3), "a imprensa brasileira encontra muito mais incentivos para intervir diretamente na vida política e legal do país, influenciando as instituições a atuarem na direção "certa”, do bem comum”.

Com a influência exercida por outros poderes que não os democráticos tradicionais, para as tomadas de decisão que influenciarão significativamente a vida das pessoas, especialistas como Rodrik (2000), Cerny (1995) e Strange (1996), acreditam, como expressam em seus respectivos trabalhos, em um declínio do Estado democrático de direito tal como o conhecemos hoje, causado pela corrente mudança da autoridade política e pelas novas relações transnacionais. 
Há que se considerar que as medidas restritivas criadas para combater a crise econômica, sobretudo na Europa, afetaram a vida das pessoas, especialmente porque representaram renúncia a várias benesses sociais. Nesse aspecto, e se considerado que, apesar de formalmente legais - porque obedeceram às normas previstas -, não representaram em sua maioria a efetiva vontade de grande parte dessas populações, não estariam democraticamente legitimadas.

Pode-se pensar, portanto, em uma falta de legitimação ou em um retrocesso do patamar democrático que foi alcançado a partir das ideias iluministas que forjaram a modernidade. Assim, essa dedução precipitaria uma conclusão de diminuição da atuação democrática dos Estados, ou fragilização da própria Democracia (Faria, 2004, p. 34).

Os levantes populares nos países muçulmanos em busca de maior liberdade de expressão e de participação nas decisões políticas, ou mesmo as revoltas e manifestações que se espalharam recentemente pela Europa em razão das medidas extintivas ou restritivas de benefícios sociais, parecem indicar, como bússola, que a Democracia representativa, eleita pela imensa maioria dos Estados democráticos de direito, está em declínio. Os representantes do povo parecem representar apenas o interesse de pequenos grupos ou classes, diminutos no aspecto da dimensão populacional, mas fortes e poderosos se mensurados do ponto de vista econômico e de influência política. ${ }^{9}$

${ }_{9}^{9}$ Como analisa Epstein: "As mazelas que a democracia representativa tem exposto em vários países como a corrupção dos representantes eleitos, a existência de grupos lobistas com grande poder e disposição para o suborno, sugerem mudanças [...]”. In: Epstein, Isaac. O paradoxo de Condorcet e a crise da democracia representativa. Estudos Avançados, São Paulo, v. 11, n. 30, ago. 1997. Disponível em: <http://www.scielo.br/scielo.php?script=sci_ arttext\&pid=S0103-40141997000200017\&lng=en\&nrm=iso >. Acesso em: 18 fev. 2013. 
A ideia de que a manutenção do crescimento econômico e da riqueza monetária a qualquer custo, ainda que tal represente a possibilidade de ataque à Soberania do Estado, ou mesmo violação ao princípio básico da Democracia, de que a tese política vencedora será a tese da expressiva maioria, parece não ser a mais consentânea e nem representar a medida mais adequada ante às vicissitudes da vida globalizada pós-moderna. ${ }^{10}$

As crises se sucederão, as transformações serão frequentes e períodos de instabilidade econômica e política não poderão ser evitados. O momento presente, todavia, parece indicar que o caminho a ser trilhado deve ser o do resgate de princípios e valores fundadores dos propósitos de harmonia, paz, boa convivência e prosperidade na qualidade de vida das pessoas. Todos esses objetivos dever ser alcançados a partir dos propósitos republicanos, do bem comum, expressados a partir de uma Democracia legitimada no aspecto material.

O alcance desse patamar trará melhores condições de enfrentamento a esses períodos de instabilidade, sem que exista ameaça a um desses referidos princípios fundadores: a Soberania do ente estatal. Mesmo quando se pensa em união de Estados em mercados comuns ou em reunião estrutural de instituições, como no exemplo europeu, a Soberania individual do ente estatal deve ser preservada, respeitada e mantida. Não parece haver incongruência nesses propósitos.

\footnotetext{
${ }^{10}$ Explica Schmitz: “O Principio Republicano orienta todo o ordenamento jurídico a partir da premissa de que, em qualquer situação jurídica, deve sempre prevalecer o Interesse da Maioria". In: Cruz, Paulo Márcio; Schmitz, Sérgio Antonio. Sobre o Princípio Republicano. p. 45. Disponível em: <siaiweb06.univali.br/seer/index.php/nej/article/download/1226/1029>. Acesso em: 18 jan. 2013.
} 


\section{CONSIDERAÇÕES FINAIS}

A ideia de Soberania dos Estados está intrinsecamente ligada à ideia central de concepção do próprio Estado, porquanto essa organização tem como função as tomadas de decisão políticas a partir das aspirações da população que representa para atender a esses anseios e alcançar um melhor patamar e qualidade de vida. Tais decisões, portanto, haverão de ter berço definido e preponderante no palco da atividade do ente estatal.

Em tempos atuais, crises econômicas derivadas de má gestão ou de contingências relativas a fluxos econômicos têm atingido vários Estados, inclusive aqueles com maior capacidade econômica ou história política, como alguns Estados europeus. Na busca por soluções a essas turbulências, tem-se verificado o enfraquecimento da Soberania dos Estados à medida que seus governos cedem às pressões dos grandes grupos financeiros ou econômicos pela tomada de medidas austeras que restringem direitos sociais alcançados ao longo de décadas de formação dos Estados sociais democráticos de direito.

Essa perda da capacidade soberana do Estado em tomar as decisões que lhe pareçam mais convenientes, à luz dos interesses locais - e não externos ou de grupos - reflete, ainda, uma fragilização da Democracia, evidenciada e comprovada pelas inúmeras e eloquentes manifestações populares, notadamente na Europa, atingidas pelas referidas medidas. Desse modo, ainda que se entenda que um regime democrático deve conviver harmonicamente com as divergências dos grupos vencidos, o que se vê é que os grupos cujas ideias de preservação de um determinado modelo econômico a qualquer custo são minoritários, não alcançariam sucesso em seus propósitos políticos caso não estivessem escudados em fortes conglomerados econômicos e financeiros. 
Surge, portanto, a hipótese de que a Democracia, considerando esse enfraquecimento da Soberania dos Estados, tem experimentado sérios desafios, inclusive na Europa. Todo esse processo vem sendo ainda mais exposto com o advento da globalização, que facilitou a atuação dos grandes blocos econômicos em todas as partes do planeta, que acabaram transformando-se em agentes influenciadores no processo democrático de criação e manutenção de um ordenamento jurídico que outrora defendia os interesses dos integrantes da sociedade.

Cogita-se, dessa forma, que a busca por um modelo econômico que atenda prioritariamente aos interesses dos grandes grupos econômicos mundiais tem mostrado o caminho político - no campo econômico e social - a ser trilhado pelos Estados, que, assim agindo, abrem mão de seu poder soberano de decisão. Essa tendência bem-evidenciada recentemente na Europa mostra a fragilidade do modelo político de Soberania e de Democracia que a modernidade concebeu. Essa situação traz ao cientista do Direito o desafio de pensar que esse período de transformações exige um "revisitar" aos conceitos fundamentais de formação do Estado, do modo de exercício de sua Soberania e da maneira como será efetivada a Democracia, de modo a legitimar as tomadas de decisão e trazer à população garantias de que a manutenção e a busca por uma qualidade de vida não serão esquecidas.

\section{REFERÊNCIAS}

ALBUQUERQUE, Afonso de. Um outro “Quarto Poder”: imprensa e compromisso político no Brasil. 2000. Disponível em: <http://www.plataformademocratica.org/Publicacoes/12770_Cached.pdf>. Acesso em: 18 jan. 2013.

BECK, Ulrich. O que é globalização? Equívocos do globalismo. Respostas à Globalização. Tradução André Carone. São Paulo: Paz e Terra, 1999. 
BIERNAZKI, Willians. Globalização da comunicação: poder global das empresas transnacionais de mídia questiona o papel dos Estados Nacionais e a identidade dos diferentes povos do mundo. Comunicação e Educação, São Paulo, (19): 46 a 65, set. /dez. 2000.

BUDEL, Cristiane. Flexibilização da legislação trabalhista: uma ameaça à dignidade da pessoa humana. 2002. Disponível em: <http://www.trt9.jus. br/internet_base/arquivo_download.do?evento=Baixar\&idArquivoAnexado $\mathrm{Plc}=1473151>$. Acesso em: 18 jan. 2013.

CAMBRAIA, Hudson de Oliveira. A globalização, seus reflexos na soberania dos Estados e na institucionalização do Estado Democrático de Direito e os blocos internacionais: a viabilização de uma alternativa possível. Revista Eletrônica Virtuajus, PUC Minas. Disponível em: <http://www.fmd.pucminas. br/Virtuajus/1_2008/Discentes/Globalizacao.pdf>. Acesso em: 15 jan. 2013.

CERNY, Philip. Globalization and the changing locig of collective action. International Organization, 49 (4), p. 595-625, 1995.

CLEVELAND, Clayton J. Globalization and Sovereignty: the persistance of an international norm. Eugene: University of Oregon, 2006.

CRUZ, Paulo Márcio. Democracia e pós-modernidade. Disponível em: <http:// www.conpedi.org.br/manaus/arquivos/anais/campos/paulo_marcio_cruz. pdf . Acesso em: 20 jan. 2013.

CRUZ, Paulo Márcio; FERRER, Gabriel Real. A crise financeira mundial, o Estado e a democracia econômica. Argumentum - Revista de Direito, n. 10, p. 117-136, 2009.

CRUZ, Paulo Márcio; SCHMITZ, Sérgio Antonio. Sobre o princípio republicano. Disponível em: < siaiweb06.univali.br/seer/index.php/nej/article/download/1226/1029>. Acesso em: 18 jan. 2013.

CRUZ, Paulo Márcio; XAVIER, Grazielle. Democracia transnacional. 2008. Disponível em: <http://www.conpedi.org.br/manaus/arquivos/anais/salvador/ paulo_marcio_cruz.pdf>. Acesso em: 15 jan. 2013.

DUPAS, Gilberto. A crise econômica internacional, o desenvolvimento e a democracia. Cadernos do NUPPs, USP, ano 1, n. 1, mar. 2009. 
FARIA, José Eduardo. O direito na economia globalizada. São Paulo: Malheiros, 2004.

FERRAJOLI, Luigi. A soberania no mundo moderno. São Paulo: Martins Fontes, 2002.

GIDDENS, Anthony. As consequências da modernidade. São Paulo: Unesp, 1991.

GIDDENS, Anthony. O Estado-nação e a violência. São Paulo: Edusp, 2001.

HABERMAS, Jürgen. A inclusão do outro: estudos de teoria política. São Paulo: Loyola, 2002.

JOFFE, George. A primavera árabe no Norte de África: origens e perspectivas de futuro. Relações Internacionais, Lisboa, n. 30, jun. 2011. Disponível em: $<$ http://www.scielo.gpeari.mctes.pt/scielo.php?script=sci_arttext\&pid=S1645-91992011000200006\&lng=pt\&nrm=iso >. Acesso em: 18 jan. 2013.

MELLO, Valérie de Campos. Globalização, regionalismo e ordem internacional. Revista Brasileira de Política Internacional, Brasília, v. 42, n. 1, jun 1999. Disponível em: <http://www.scielo.br/scielo.php?script=sci_ arttext\&pid=S0034-73291999000100007\&lng=en\&nrm=iso >. Acesso em: 15 jan. 2013.

RESENDE, Carlos Alberto. Jürgen Habermas e a crise do estado globalizado. 2011. Disponível em: <http://www.diritto.it/docs/31317-j-rgen-habermas-e-a-crise-do-estado-globalizado >. Acesso em: 15 jan. 2013.

RODRIK, Dani. Governance of Economic Globalization. In: NYE, Joseph; DONAHUE, John. Governance in a Globalizing World. Washington, DC: Brookings, 2000. p. 367-365.

STAL, Eva; CAMPANARIO, Milton de Abreu. Empresas multinacionais de países emergentes: o crescimento das multilatinas. Economia global e gestão, Lisboa, v. 15, n. 1, abr. 2010. Disponível em: <http://www.scielo.gpeari.mctes. pt/scielo.php?script=sci_arttext\&pid=S0873-74442010000100004\&lng=pt\&nr $\mathrm{m}=$ iso $>$. Acesso em: 17 jan. 2013. 
STRANGE, Susan. The Retreat of the State: The Diffusion of Power in the World. New York City: Cambridge University Press, 1996.

THE GUARDIAN. EU should control member states' budgets, says bank boss. 2011. Disponível em: <http://www.guardian.co.uk/business/2011/jun/02/ trichet-wants-eu-central-finance-ministry>. Acesso em: 15 jan. 2013.

UNIÃO EUROPEIA. A história da União Europeia. 2006a. Disponível em: $<$ http://europa.eu/about-eu/eu-history/index_pt.htm>. Acesso em: 15 jan. 2013.

UNIÃO EUROPEIA. Assuntos institucionais: trabalhar em conjunto. 2006b. Disponível em: <http://europa.eu/pol/inst/index_pt.htm>. Acesso em: 15 jan. 2013.

UNIÃO EUROPEIA. Informações gerais sobre a União Europeia. 2006c. Disponível em: <http://europa.eu/about-eu/basic-information/index_pt.htm>. Acesso em: 16 jan. 2013.

Recebido em: 15/3/2013

Aceito em: 27/8/2013 